\title{
Interdisciplinaridade: um novo paradigma do conhecimento?
}

\author{
Sônia Maria Marchiorato Carneiro ${ }^{*}$
}

\section{Introdução}

O objetivo de concatenar algumas reflexões sobre a questão da interdisciplinaridade responde uma necessidade pessoal, no âmbito da própria necessidade que os profissionais vêm sentindo nos seus respectivos campos de trabalho quanto à busca de novos referenciais analíticos e interpretativos frente aos complexos desafios do mundo presente. A bibliografia temática ainda é relativamente escassa, pois a interdisciplinaridade é nova como campo de estudos, a despeito do interesse que vem mundialmente despertando na pesquisa e na Educação.

O presente texto compõe-se de três partes, enfocando a interdisciplinaridade em termos gerais, mas aliada principalmente à questão do saber ambiental, que é hoje uma perspectiva recorrente em todos os campos de conhecimento.

A primeira parte ocupa-se da relação homem-natureza: concepções diacrônicas, ações antrópicas derivadas e urgência de uma mudança de entendimento da problemática ambiental. A segunda trata do conhecimento interdisciplinar como uma dimensão nova e necessária ao pensamento atual sobre o meio ambiente, constituindo já um saber ambiental; são destacados alguns princípios de concepção e prática interdisciplinar, com alusão à situação de diferentes áreas de conhecimento nessa perspectiva.

* Professora do Departamento de Métodos e Técnicas da Educação, Universidade Federal do Paraná. 
E a última parte traça um rápido inventário dos obstáculos à interdisciplinaridade, em vista da sua superação em benefício da qualidade de vida humana no mundo de hoje.

\section{A relação homem-natureza}

Mais do que em outras épocas a sociedade está hoje se ressentindo dos problemas ambientais que afetam direta ou indiretamente a qualidade de vida. Sabe-se em nossos dias que, pela poluição, pelo uso ilimitado dos recursos naturais e pela urbanização acelerada - entre outros fatores - a agréssão à natureza e às populações atinge níveis catastróficos, com uma deterioração quase planetária e que ameaça a própria vida sobre a Terra (Buarque, In: Bursztyn, 1993, p.66). Como aconteceu chegar o homem ao ponto de autoprejudicar-se no próprio anseio de desenvolvimento?

No decorrer dos tempos o homem tem tido diferentes concepções do mundo, do ambiente de vida, da natureza. Suas atitudes, nesse sentido, apresentam variações através das épocas e entre culturas de uma mesma época. Os povos não-letrados viam e ainda vêem a natureza como divina e, por isso, merecedora de respeito e até para ser temida (Drew, 1989, p. 1-4). Já o pensamento moderno se forma, desde suas bases na civilização grega, com uma orientação economicista e antropocêntrica que visualiza a natureza como elemento a ser conquistado em proveito máximo do homem. Nessa perspectiva, a partir da Revolução Industrial tem-se intensificado o afã humano de entender a natureza para dominá-la e transformá-la em bens e serviços (Buarque, In: Bursztyn, 1993, p.66). Este modo de pensar do homem contemporâneo expressa uma concepção de natureza como fonte inesgotável de recursos e receptáculo de resíduos com capacidade ilimitada (Clemente e Juchem, 1993, p.1-2). Desde os anos 60, no entanto, vem emergindo uma conscientização social sobre a gravidade dos problemas ambientais desencadeados pelo progresso e pelo desenvolvimento material, com crescente percepção do risco de autodestruição do próprio homem (Jollivet e Pavé, 1992, p.6; Buarque, 1991, p.121). Esse movimento ecológico-ambientalista de amplitude mundial, que atingiu o Brasil na década de 70, questiona as presentes condições de vida - com a extinção de espécies biológicas, o desmatamento, a erosão dos solos, a poluição do ar e da água, a contaminação dos próprios alimentos e muitos outros problemas (Gonçalves, 1990, p.11-3).

Dentre as várias abordagens sobre a relação homem-natureza, a partir da década de 60, destacam-se: o biocentrismo, oposto ao forte antropocen- 
trismo anterior à década de 60 , constituindo a chamada ecologia profunda ou radical e que concebe o homem em igualdade com as outras espécies vivas e enfatiza a necessidade de se estabalecer limites ao crescimento econômico e demográfico; as correntes que se situam entre o antropocentrismo extremo e o biocentrismo:

a - a proteção ambiental, com ênfase antropocêntrica e que propõe um compromisso entre o crescimento econômico e o cuidado pela natureza por meio de uma "agenda defensiva e de taxações para remediar os impactos ambientais";

b - a gestão de recursos (paradigma do relatório Bruntland), de caráter antropocêntrico relativizado e que propõe a necessidade de um crescimento verde em razão da "degradação recursos, da pobreza no Sul e da necessidade de uma eficiência global", através de menos consumismo dos países centrais e de uma redução demográfica nos países periféricos;

c - o ecodesenvolvimento, relacionado ao ecocentrismo e que postula a necessidade de um co-desenvolvimento de homem e natureza, ou seja, "ecologizar o sistema social" (Becker e Gomes, In: Vieira, 1993, 116-7).

Deve-se observar ainda que dois momentos se destacam nesses movimentos sociais no decorrer dos últimos trinta anos. O primeiro acontece nos final dos anos 60 , caraterizado por uma visão concentrada na proteção ambiental, de par com uma prospectiva caótica do mundo se os sistemas produtivos e o comportamento humano frente à natureza não se transformassem. O segundo momento vem dos anos 70 aos nossos dias, marcado pela crescente percepção de que a capacidade humana de deterioração ambiental é maior do que se pensara inicialmente, se bem que não infinita; de outra parte, a questão ecológica tem-se interligado mais e mais com o desenvolvimento social e econômico, encontrando expressão através dos enfoques e propostas de desenvolvimento sustentável (Viola, In: INEP, 1992, p.104-5).

$\mathrm{Na}$ realidade, a idéia de desenvolvimento sutentável envolve diversas interpretações. Mas pode-se destacar como básicas as dimensões de qualidade de vida e de utilização racional dos recursos naturais, aliadas à questão político- econômica. Esta perspectiva de reencaminhamento das sociedades hodiernas demanda um desenvolvimento sustentável, a efetivar-se por meio de uma política interessada em harmonizar a economia e a ecologia, com base nas possibilidades da ciência e da tecnologia. E tal política supõe e exige uma ética ambiental a ser promovida e alcançada não só, evidentemente, mas também pela educação (Mendes, p. 22-3; Becker, In: Bursztyn, 1993, p. 13035 e 142). Nesse contexto sócio-político e econômico torna-se urgente uma nova epistemologia que incorpore o saber dos diversos segmentos da sociedade como base o da idéia de um desenvolvimento sustentável, em vista da 
melhoria da qualidade de vida do homem,isto é, das condições sócio-ambientais do mundo.

\section{O conhecimento interdisciplinar}

A construção de um conhecimento interdisciplinar, entre outros processos sociais, é de fundamental importância na análise e resolução dos problemas ambientais. Nas últimas décadas, com efeito, tem ocorrido um debate epistemológico em todos os campos de especialização científica sob uma perspectiva interdisciplinar, em vista de uma maior compreensão e domínio da problemática ambiental. Um saber ambiental, com efeito, implica um conjunto de disciplinas, tanto das ciências naturais quanto das sociais, para a construção de um conhecimento capaz de abranger a multicausalidade e as relações de interdependência dos processos naturais e sociais determinantes das mudanças sócio-ambientais e, portanto, um conhecimento que possibilite por sua vez a construção de uma racionalidade ambiental produtiva, baseada em princípios de um desenvolvimento sustentável, justo e duradouro. O saber ambiental, pois, envolve um pensamento e uma metodologia interdisciplinares, pelo fato de necessitar da articulação dos diferentes campos de conhecimento para a compreensão dos processos físicos, biológicos, culturais e sócio-econômicos, juntamente com uma consciência crítica voltada a um propósito estratégico e político para implementação de projetos de gestão ambiental e de políticas alternativas de desenvolvimento (Leff, 1993, p.95-7, 105 e 115; Jollivet e Pavé, 1992, p.7-8). A característica básica da interdisciplinaridade é dada pela "intensidade das trocas entre os especialistas e pelo grau de integração real das disciplinas no interior de um mesmo projeto de pesquisa" (Japiassu, 1976, p.74). Sob este enfoque, o conhecimento interdisciplinar é uma relação de reciprocidade, de mutualidade, ou seja, de diálogo entre os interessados em uma superação das fronteiras disciplinares. Por diálogo entende-se o respeito pela fala de cada um, pela sua forma de pensar, o esforço honesto de todas as partes em tentar se entender, o objeto concreto em torno do qual todos se debruçam (Pernambuco, In: Pontuschka, (org.), 1993, p.24).

Daí que a interdisciplinaridade dependa fundamentalmente de uma atitude de colaboração dos pesquisadores frente ao desafio de uma prática coletiva, com o objetivo de se produzir conhecimento novo, unitário e crítico. A interdisciplinaridade, portanto, não é uma ciência nem ciência das ciências, mas um paradigma metodológico que visa a um encontro entre especialistas de diversas áreas do conhecimento, numa perspectiva de se 
buscar respostas a novos problemas por meio da troca de dados, de informações, de resultados, de metodologias etc. (Japiassu, 1976, p.39-90; Fazenda, 1979 , p.25-50; 1993, p.39-43).

Com base em Jolivet e Pavé (1992, p.20-1), a prática da interdisciplinaridade deve ser considerada sob duas formas: um esforço comum de pesquisa conjugando diversas áreas e uma participação de diversas áreas do conhecimento num campo comum de pesquisa.

No primeiro caso, trata-se de uma cooperação entre pesquisadores de diversas áreas que decidem partilhar os resultados de suas pesquisas específicas; já a segunda forma constitui propriamente a pesquisa interdisciplinar, em torno de objetivos comuns sobre o mesmo objeto de estudo.

Na realidade, a interdisciplinaridade não é um campo de indagação recente. A idéia de um saber unitário sempre existiu na história do pensamento, emergindo tanto nas culturas antigas como na época medieval através de uma epistemologia do cosmos, em termos de visão unitária do real, mas sob concepções diferenciadas. Enquanto o homem antigo (concepção grega) considerava a realidade (natureza, homem, deuses) submetida às leis imanentes do cosmos (nada existiria fora dele), o homem medieval acreditava na transcendência do ser divino, como Deus criador e protetor do cosmos. Nos tempos modernos verifica-se uma desintegração do saber unitário, no contexto e convergência de influências do Renascimento, da Reforma e das Grandes Descobertas: o homem passa a ter consciência de si num universo indefinidamente ampliado, no qual a Terra não é mais o centro do universo e o Ocidente deixa de ser o centro da Terra; surge um novo horizonte do saber, como busca daquilo que não se sabe. Os pensadores começam a ser pesquisadores e tentam desenvolver um trabalho coletivo e complementar (as academias e sociedades científicas e culturais do século XVII e o enciclopedismo do séc. XVIII), marcando um momento em que uma visão unitária, interdisciplinar, do saber aparecia como uma urgência histórica ante a fragmentação do conhecimento. No século XIX, porém, com a própria expansão dos trabalhos científicos e a ampliação das especulações teóricas, a visão de um saber unitário torna-se cada vez mais precária, cedendo lugar à divisão especializada das ciências (Fazenda, 1979, p.25-6 e 51-3; Japiassu, 1976, p.45-8).

Mas a aspiração pela unidade do conhecimento continuava subjacente à divisão do trabalho epistemológico e passa a ser recuperada nesta segunda metade do século em curso. A busca do saber interdisciplinar decorre da necessidade que o homem experimenta em compreender as condições e 0 sentido de sua existência no tempo presente, para decidir e atuar a partir de e sobre essas condições, em vista de transformações até mesmo prementes. A magnitude interativa dos fenômenos sociais e naturais do mundo atual 
escapa ao âmbito de análise e interpretação das áreas de conhecimento setorializadas e exige mais e mais uma interação produtiva entre os especialistas. Assim é que a complexidade das condições existenciais do homem de hoje demanda uma real colaboração das ciências naturais e sociais para uma leitura global e interpretativa do meio ambiente (Arizpe, 1991, p.641-6).

Várias são já as ciências que vêm concretizando trabalhos interdisciplinares em torno da questão ambiental. Entre elas a Biologia, a Química, a Engenharia e a Física, em todas as especialidades. De outro lado, as Ciências Sociais e Matemáticas ainda não se encontram suficientemente envolvidas com pesquisas sobre o meio ambiente. As primeiras ciências a se envolver com as questões ambientais foram as denominadas ciências da vida: Biologia e Ecologia. Em conexão com elas, surgiram movimentos militantes, dentre os quais os ecologistas políticos têm sido os mais ativos e radicais em denunciar os perigos que a humanidade e todos os seres vivos estão correndo por causa da assustadoramente crescente degradação ambiental. A biodiversidade e as relações organismo-meio são focos de atenção dos cientistas desta área, que se voltam aos efeitos, reações e transformações do meio ambiente sob a ação do homem.

A Química também tem estado bastante envolvida com as questões ambientais, em vista da sua relação com o setor industrial na produção de materiais que podem afetar o ambiente; assim, ela tem se dedicado particularmente ao estudo das alternativas de despoluição dos meios industriais.

As Ciências de Engenharia vêm contribuindo significativamente com as tecnologias hidrodinâmica, acústica e aerodinâmica para a efetivação de projetos de saneamento e conservação ambiental. Notável é ainda o aporte desta área na elaboração de um instrumento universal baseado na trilogia modelo, análise e controle com vistas ao desenvolvimento de projetos que compatibilizem avanços de tecnologia industrial e as necessidades ambientais.

A Informática e a Automação estão pouco a pouco sendo incorporadas ao tratamento das questões ambientais: a primeira, na gestão de dados sobre situações dos ambientes, na modelização e simulação analítico-projetivas de problemas globais e setoriais; e a segunda, principalmente na análise e teoria de sistemas aplicadas à complexidade das problemáticas ambientais.

As Ciências do Universo e as Ciências Físicas (ciências do solo, da atmosfera e oceanografia, entre outras) vêm desenvolvendo pesquisas relativas às mudanças globais da Terra, sob uma perspectiva de passado e presente das transformações do ambiente e as conseqüências delas decorrentes. Tais estudos têm possibilitado avanços metodológicos utilizáveis em outras áreas de conhecimento. 
Apesar das Ciências Matemáticas aparecerem até o presente pouco comprometidas com os estudos ambientais, são fundamentais para a construção de modelos, o desenvolvimento de análises de processos e sistemas complexos e o tratamento de dados em processos de decisão referenciados a critérios probabilísticos.

Pelo fato de que os problemas ambientais advêm de ações antrópicas, é de importância crucial a colaboração das Ciências Sociais aos estudos do meio. As pesquisas neste campo, no entanto, são ainda insuficientes. Nesta área, a Economia, o Direito e a Sociologia são as ciências que mais avançaram na problemática ambiental. Outras, como a Geografia, a História, a Filosofia, a Antropologia, a Psicologia Social e a Demografia, só recentemente vêm tendo envolvimento com as questões do meio ambiente. (Jollivet e Pavé, 1992, p.21-4; Vieira, 1993, p.31-2).

Dentre as contribuições das Ciências Sociais aos estudos ambientais destacam-se algumas perspectivas ou dimensões. Assim, a Economia tem enfocado a questão do máximo rendimento sustentável, avaliando o impacto ambiental de políticas, programas e projetos de desenvolvimento; os conceitos de capital natural e função de danos são valiosos na construção de uma nova economia ecológica. No âmbito da Sociologia, sobressaem especialmente a análise dos movimentos ambientalistas, a avaliação de impactos ambientais, e educação ambiental e participação política, assim como a integração da problemática ambiental ao debate teórico e metodológico, em vista da legitimação dos princípios da racionalidade ambiental. A Geografia igualmente tem-se ocupado em avaliar impactos ambientais relativos a políticas, programas e projetos de desenvolvimento, em realizar análises espaciais e planejamento, bem como em integrar a problemática ambiental no debate teórico e metodológico; os geógrafos ambientalistas têm desenvolvido estudos de percepção ambiental e da ação antrópica( por exemplo, nos processo geomorfológicos) e estão trabalhando com sistemas geográficos de informação, já em perspectiva interdisciplinar. A Geografia e a Ecologia vêm se aproximando num sentido de espacialização da Ecologia, de modo a melhor captar os mecanismos de apropriação dos recursos naturais e poder construir unidades operacionais de manejo desses recursos. No campo da História, as maiores contribuições aos estudos do meio estão relacionadas com o paleomeio-ambiente, no contexto de pesquisas arqueológicas, paleontológicas e da Antropologia Histórica. A Filosofia tem tratado a questão ambiental sob os aspectos teórico e metodológico e, mormente, na dimensão ética das decisões e responsabilizações pessoais e coletivas do uso e apropriação do meio ambiente. A Antropologia vem-se preocupando com a avaliação dos impactos ambientais, desenvolvendo estudos com a Ecologia (Antropologia Ecológica) no nível da integração sociocultural e enfocando 
a articulação das organizações culturais com as condições do meio ambiente. A Psicologia Social, por sua vez, vem-se dedicando à análise das representações do meio e, por sua parte, a Demografia tem estudado as relações do processo de desenvolvimento com a dinâmica demográfica e as condições ambientais (Jolivet e Pavé, 1992, p.23-4; Vieira, 1993, p.31-2; Leff, 1993, p.120-3; Becker e Gomes, 1993, p.159).

A relação ciências-meio ambiente, portanto, já alcança uma explicitação bastante significativa em todos os campos do conhecimento. E por isso mesmo tanto mais a questão da interdisciplinaridade se coloca de maneira crucial nos dias de hoje.

\section{Interdisciplinaridade: obstáculos e possibilidades}

Se a interdisciplinaridade é um avanço epistemo-metodológico produtivo, é também difícil de ser alcançada ante os vários obstáculos que se lhe antepõem. São obstáculos epistemológicos e institucionais, psicossociológicos e culturais, metodológicos, materiais e de formação profissional (Gusdorf, In: Japiassu, 1976, p.94; Fazenda, 1979, p.52-7).

Os obstáculos epistemológicos e institucionais estão relacionados, sobretudo, a uma atitude de resistência das instituições de ensino, de pesquisa e dos próprios especialistas em instituir ou, ao menos, estabelecer, aproximações, comunicações, confrontos e integração entre as disciplinas curriculares e, mais ainda, entre as ciências. Apesar de que a fragmentação do conhecimento seja considerada um reflexo dos valores sociais do mundo atual, o que impede de fato a eliminação de barreiras entre as ciências é, basicamente, o comodismo - pois, segundo Gusdorf, é mais fácil trabalhar intelectualmente sob forma parcelada do que entrar num processo dialógico quanto às idéias alheias e em relação às próprias (Fazenda, 1979, p.53).

Para superar o distanciamento entre os diversos campos de conhecimento, o esforço interdisciplinar necessariamente prevê uma convergência, uma co-participação das ciências na colocação dos problemas de interesse por meio de uma linguagem comum e em perspectiva de confronto, de complementação metodológica, de partilhamento de conceitos, de estruturas de conteúdos e de axiomas e pressupostos. A interdisciplinaridade não se institui, portanto, pela perda da competência específica de cada disciplina ou de uma ciência; mas sim por uma articulação suficiente de competências que, concatenadas produtivamente, iriam formar um anel completo e dinâmico - uma comunicação de reflexão conjugada (Japiassu, 1976, p.90 e In: Fazenda, 1979, p.52-4; Morin, s.d., p.33). 
A superação dos obstáculos psicossociológicos e culturais implica em transformar a mentalidade das pessoas envolvidas com a produção e disseminação do conhecimento. Até pouco ocorria um claro preconceito frente à adesão de um(a) especialista a um trabalho de natureza interdisciplinar, principalmente pelo temor de se dissipar a especialização. A compreensão do real significado de um projeto interdisciplinar é, por conseguinte, uma das estratégias básicas para que os especialistas percebam as relações de sua área com as demais, avaliando e efetivando as contribuições a ser compartilhadas. A partir desta nova atitude, pode-se eliminar os obstáculos metodológicos, que se opõem à efetivação de uma pesquisa interdisciplinar como tal. O passo inicial para tanto será o conhecimento que os membros de um projeto interdisciplinar deverão ter da instrumentação metodológica de cada área envolvida, de modo que todos possam visualizar de maneira clara e assumir sua contribuição e grau de participação no trabalho conjunto. Todos os dados coletados, sob critérios e enfoques específicos, merecem consideração na análise e interpretação dos resultados de pesquisa do(s) problema(s) tematizado(s) por uma equipe interdisciplinar. Portanto, o entendimento da interdisciplinaridade é pressuposto para que um profissional compreenda as relações de sua área de conhecimento com as outras englobadas num dado projeto, visualizando as contribuições mútuas e sem a necessidade de ser um especialista múltiplo.

Os procedimentos metodológicos imbricam-se com os obstáculos materiais, ou de disponibilidades operacionais, normalmente resultantes de um planejamento inadequado relativamente às questões de espaço e tempo, de recursos técnicos e econômico-financeiros - estes, fundamentais para a motivação dos participantes de uma projeto (Japiassu, 1976, p.137-8; Fazenda, 1979, p.54-7).

Os obstáculos relacionados à formação profissional, entretanto, constituem a fonte de derivação e manutenção dos anteriores. Com efeito, os vieses curriculares estabelecidos e institucionalizados nos programas de formação de pesquisadores, nas diversas áreas de conhecimento, consagram o disciplinarismo e a especialização estanque como princípios intocáveis. No contexto, porém, da atual premência de um saber ambiental - necessariamente interdisciplinar - é hora de se repensar e avaliar os objetivos e programas curriculares de formação dos profissionais de hoje para amanhã, nos diversos campos e graus de conhecimento e ensino. O fundamental é a leitura crítica da realidade de hoje, em sua globalidade e concretudes localizadas, com vistas à construção - inicialmente pelas instituições e pessoas responsáveis - das condições de conhecimento que a sociedade hodierna necessita para compreender melhor o mundo e agir com intencio- 
nalidade explícita e referenciada à participação democrática nas decisões sócio-estruturais e ambientais. A orientação interdisciplinar possibilitará ao educando-cidadão, de qualquer nível escolar, a elaboração progressiva de uma apreensão global e integrada da realidade de vida - experienciando uma identidade entre 0 vivido e 0 estudado, num processo de conscientização ambiental, com implicações de crenças e valores (Fazenda, 1979, p.41-9, 55-6; Japiassu, 1976, p.138-141; Leff, 1993, p.97, 104, 116 118; Jolivet, 1992, p.26).

Na perspectiva delineada sobre a interdisciplinaridade, avulta o desafio do tempo presente à Educação, pois dela se exige que "seja capaz de educar ou humanizar a modernidade", de modo que as inovações necessárias se fundamentem na produção e no manejo de conhecimentos em vista da qualidade de vida - que é, em síntese, a efetivação da cidadania (Demo, a, 1993:04; b, 1993, p.19-21; c, 1993, p.70-1).

\section{REFERÊNCIAS BIBLIOGRÁFICAS}

ARIZPE, Lourdes. Le cube planétaire. Revue Internationale des Sciences Sociales, Paris : Unesco, 20p., nov. 1991.

BUARQUE, Cristovam. A desorden do progresso: o fim da era dos economistas e a construção do futuro. Rio : Paz e Terra, 1990. 186 p.

BURSZTYN, Marcel (org.) Para pensar o desenvolvimento sustentável. São Paulo: Brasiliense, 1993. $161 \mathrm{p}$.

CLEMENTE, Ademir, JUCHEM, Peno Ari. Valoração econômica do meio ambiente. Curitiba, 1993. Mestrado em Desenvolvimento Econômico. Departamento de Economia, Setor de Ciências Sociais Aplicadas, Universidade Federal do Paraná, 20 p. (texto xerográfico).

DEMO, Pedro. Pesquisa participante: discutindo êxitos e dubiedades. Conferência Brasília, MJ/DSCJ, 1993. (Texto mimeografado).

DESAFIOS modernos da educação. Petrópolis : Editora Vozes, 1993. 272 p.

DESENVOLVIMENTO e educação ambiental. Brasília : INEP, 1992. 183 p. (Série Encontros e Debates, 6).

DREW, David. Processos interativos homem-meio ambiente. Trad. de João Alves dos Santos. 2 ed. Rio : Bertrand Brasil S. A., 1989. 206 p.

FAZENDA, Ivani C. A. Integração e interdisciplinaridade no ensino brasileiro: efetividade ou ideologia? São Paulo : Loyola, 1979. 107 p.

GONÇALVES, Carlos W. P. Os (des) caminhos do meio ambiente. 2 ed. São Paulo : Contexto, 1990. $147 \mathrm{p}$.

JAPIASSU, Hilton. Interdisciplinaridade e patologia do saber. Rio : Imago Editora Ltda., 1976. $220 \mathrm{p}$. 
JOLLIVET, Marcel; PAVÉ, Alain. The environment: questions and prospects for research. Environnement, 5-27, May, 1992.

MORIN, Edgar et al. O problema epistemológico da complexidade. Mem Martins (Portugal), Editora Europa-America, [s.d.] 135 p. (Biblioteca Universitária).

PARTICIPAÇÃO é conquista: noções de política social participativa. 2. ed. São Paulo: Cortez, 1993. $176 \mathrm{p}$.

PONTUSCHKA, Nídia Nacib (org.) Ousadia no diálogo. São Paulo : Loyola, 1993. $258 \mathrm{p}$.

VIEIRA, Paulo F. e MAIMON, Dália (org.) As ciências sociais e a questão ambiental: rumo à interdisciplinaridade. Rio de Janeiro, APED (Associação de Pesquisa e Ensino em Ecologia e Desenvolvimento)/Belém, UFPA, 1993. 298 p. 